\title{
HIGH VOLTAGE, HIGH CURRENT, HIGH DI/DT SOLID STATE SWITCH
}

\author{
Steven C. Glidden
}

Applied Pulsed Power, Inc.

Box 1020, 207 Langmuir Lab, 95 Brown Road, Ithaca, New York, 14850-1257

tel: 607.257.1971, fax: 607.257.5304, email: app@epix.net

\begin{abstract}
A high voltage, high di/dt, modular solid state switch intended to replace thyratrons in high power modular applications is under development. This paper describes results of testing a switch module with a $10 \mathrm{kV}, 6 \mathrm{kA}, 30 \mathrm{kA} / \mu \mathrm{s}, 3 \mu \mathrm{s}$ PFN, under normal and load fault conditions. Initial results of multiple module tests with a $30 \mathrm{kV}$ PFN are also be presented. The switch module uses $3,5 \mathrm{kV}$, $13 \mathrm{~mm}$ diameter thyristors connected in series. These thyristors were developed specifically for pulsed power applications, and have an interdigitated gate/cathode geometry to minimize turn-on losses and maximize di/dt. The module's trigger circuit uses the switched energy to drive the thyristor gates, eliminating the need for an external gate drive power supply. A $35 \mathrm{~V}, 1 \mathrm{~A}$, pulse triggers the module. The compact, modular package design facilitates the development of drop-in replacement switches for thyratrons with voltage ratings of $>60 \mathrm{kV}$.
\end{abstract}

Work supported by U.S. Department of Energy, grant DE-FG02-00ER82948.

\section{INTRODUCTION}

The goal of this project was to demonstrate the feasibility of developing a compact, high voltage, high power solid-state switch based upon newly developed thyristors. The switches consist of multiple $10 \mathrm{kV}$ modules connected in series to achieve the desired voltage rating. The switches are intended to replace thyratrons and other high current, high voltage switches in existing and new systems. The small size of the solid-state modules will enable the switches to fit within a volume similar to the thyratrons they are replacing.

The $10 \mathrm{kV}$ switch modules consist of a series array of 3 thyristors with built-in trigger circuitry. The trigger circuit uses the energy being switched to drive the thyristor gates, simplifying isolation and triggering. The elimination of the need for a separate gate drive power supply results in a straightforward process of scaling to higher voltages. The thyristors are capable of high di/dt operation without saturable inductors.

This work has shown that a $10 \mathrm{kV}$ module can operate reliably at currents up to $8 \mathrm{kA}$ at $\mathrm{di} / \mathrm{dt}$ 's of $>30 \mathrm{kA} / \mu \mathrm{s}$. The di/dt was limited by the test circuit; di/dt's of up to $80 \mathrm{kA} / \mu \mathrm{s}$ have been observed in single devices. Repetition rate operation at up to $60 \mathrm{pps}$, limited by the high voltage power supply, was demonstrated. Also it was shown that load faults, whether occurring at the beginning or middle of the pulse, did not damage the thyristors when there is some damping in the circuit. Tests at $30 \mathrm{kV}$ with three modules connected in series, showed simultaneous turn-on with good voltage-sharing between modules.

\section{0 kV MODULE DESCRIPTION}

The $10 \mathrm{kV}$ switch module consists of 3 symmetric (reverse blocking), $5 \mathrm{kV}, 13 \mathrm{~mm}$ diameter thyristors connected in series. No attempt was made to match thyristor characteristics other 
the energy being switched to drive the thyristor's gate. A $35 \mathrm{~V}, 1 \mathrm{~A}, 50$ ns risetime pulse triggers all three gate circuits. Each trigger transformer was hi-potted to $60 \mathrm{kV}$. All of the 10 $\mathrm{kV}$ module components are mounted on an $11 \times 16 \mathrm{~cm}$ circuit board.

The $13 \mathrm{~mm}$ diameter thyristors[1,2] used for the switch have been developed specifically for pulsed power applications. These devices have an extensive, serpentine gate pattern that is everywhere less than one diffusion length from the cathode, and a heavy gate connection which allows $>1 \mathrm{kA}$ gate current to minimize turn-on losses and maximize $\mathrm{di} / \mathrm{dt}$. A solid metal cathode structure efficiently collects charge during conduction, eliminating excess current density and hot spots. The device has an active area of $0.1 \mathrm{~cm}^{2}$. The positive beveling at the edge of the thyristor die acts to spread out the electric field lines on both sides of the high voltage junction when the device is forward biased.

The thyristor is packaged in a $26 \mathrm{~mm}$ square package. The anode side of the silicon chip is soldered to a metalized layer deposited on a $\mathrm{BeO}$ ceramic base. Wire-bonded cathode leads add approximately $8 \mathrm{nH}$ of cathode inductance. As a result, the gate-cathode voltage rises dramatically during high di/dt turn-on.

The $\mathrm{BeO}$ insulator that is part of the thyristor package, will hold off only $5 \mathrm{kV}$ and the heat sink is typically held at ground potential. A second layer of ceramic between the device and the heat sink provides additional voltage insulation. One mm thick AlN ceramic was used for this purpose. Several different interface materials were placed between the ceramic layers and the heat sink to improve thermal performance. For the repetition rate tests, the copper heat sinks were mounted to a water-cooled chill plate that was maintained at 22 degrees $\mathrm{C}$.

Gate drive circuits using MOSFET's, IGBT's or thyristors to switch a portion of the energy from the snubber capacitors into the thyristor gates were tested. Figure 1 shows the gate drive currents of the three thyristors for a typical pulse with a MOSFET gate switch. The abrupt decrease in gate current occurs because of the large inductive voltage drop across the cathode during turn-on, reducing the effective gate drive voltage. Experiments showed that an increase in the gate current from 60 A to 110 A decreased the total turn-on delay by $20 \mathrm{~ns}$.

\section{OPERATION WITH A NOMINAL $3 \mu \mathrm{s}, 6$ kA PFN}

Figure 2 shows typical performance using the switch to discharge a $1.68 \mu \mathrm{F}$, nominal $6 \mathrm{kA}, 3$ $\mu$ s PFN charged to $10.4 \mathrm{kV}$ into a $0.7 \Omega$ load. Two switch voltage waveforms are shown. The first is the voltage as measured by a 1000:1 high voltage probe, and the second (bold) waveform is this voltage minus the $\mathrm{L}$ di/dt inductive voltage drop across the switch. This second waveform is used to determine the energy deposited in the switch during turn-on, and for comparisons of switch turn-on at different currents. The maximum di/dt of $27 \mathrm{kA} / \mu \mathrm{s}$ is limited by the circuit.

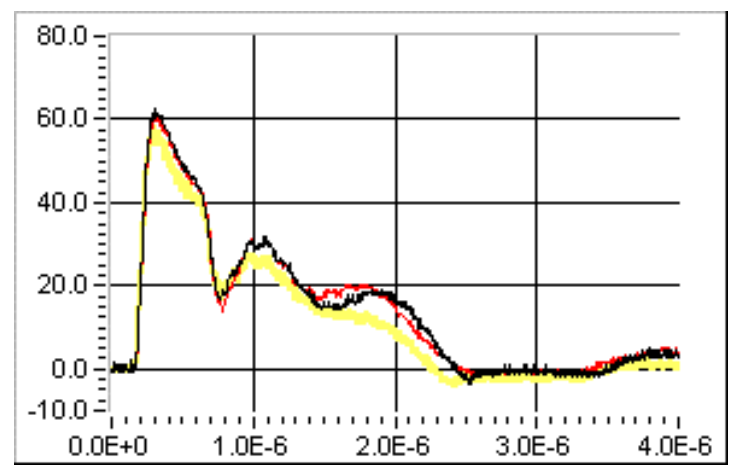

(a) Gate drive currents(A) waveforms.

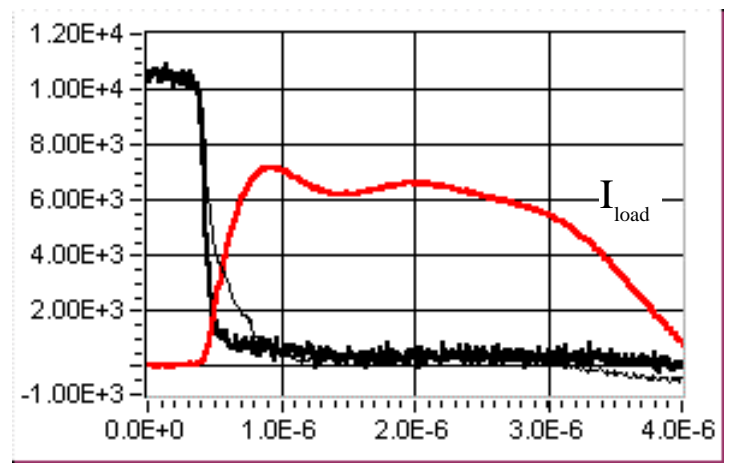

(b) Switch voltage(V) and load current(A)

Figure 1 Typical switch performance with a $1.68 \mu \mathrm{F}$ PFN charged to $10.4 \mathrm{kV}$. 


\section{TURN-ON DELAY AS A FUNCTION OF VOLTAGE AND CURRENT}

The module's turn-on delay and voltage falltime as a function of current were observed by using the three different PFNs (0.56, 1.12 and1.68 $\mu \mathrm{F}$, nominal $3 \mu$ s pulsewidth) charged to the same voltage. As indicated in Figure 2, these times are unaffected by the circuit impedance over the range from 0.88 to $2.6 \mathrm{ohms}$.

The module turn-on delay time is a strong function of the voltage across the module. To a lesser extent, the voltage falltime also increases as the voltage decreases. Data taken with the $6 \mathrm{kA}$ PFN at several different voltages is compared in Figure 3. Operation at module voltages below about $3 \mathrm{kV}$ is undesirable, as the voltage falltime begins to increase.

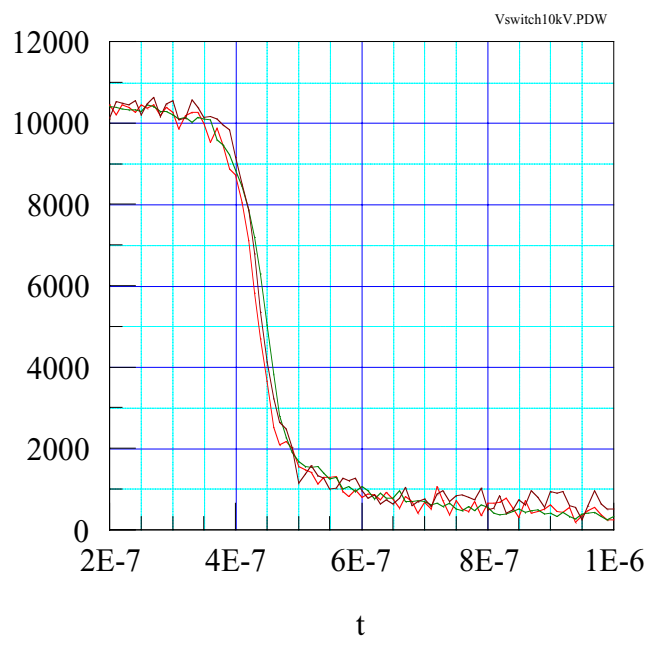

Figure 2. Effects of switch current on turn-on delay and voltage falltime for nominal $2 \mathrm{kA}, 4$ kA and 6kA PFN's.

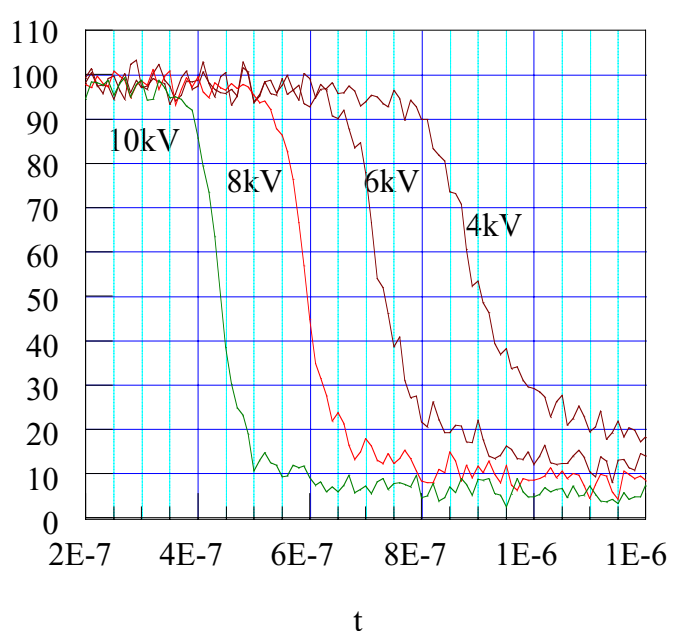

Figure 3. Effects of switch voltage on turn-on delay and voltage falltime with $1.68 \mu \mathrm{F}$ PFN

Turn-on delay is partially caused by the time required for minority charges (electrons) to transit the $\mathrm{p}$ base of the thyristors. Field-aided drift theory states that this time can be reduced by a high electric field, which increases the drift velocity of minority carriers across the bases, and thereby speeds up the turn-on. If the field is small, the charge transits by diffusion or $\mathrm{W} 2 / 2 \mathrm{D}$, where $\mathrm{W}$ is base width and $\mathrm{D}$ is the diffusion constant. If a high field is present, than transit velocity is increased proportional to electric field.

Similarly, high di/dt current, from either the snubber capacitors or the external circuit can speed the later stages of turn-on. The high current generates a large electric field in the wide $n$ - base, increasing the velocity of the holes crossing it.

\section{VOLTAGE SHARING}

Figure 4 shows the dynamic voltage sharing between the three thyristors in a $10 \mathrm{kV}$ module. All three devices turn on together. In Figure 5, a shunt resistor has been added across one thyristor to deliberately produce a mismatch in the DC voltage. As a result, this thyristor has a longer turn-on delay. Nevertheless, none of the devices see excessive voltage during turn-on. The field-aided turn-on mechanism helps to insure that any thyristor initially bearing a greater percentage of the module voltage, due perhaps to changes in leakage current as the devices heat up, will always be the first to turn-on and thus not see additional voltage. 


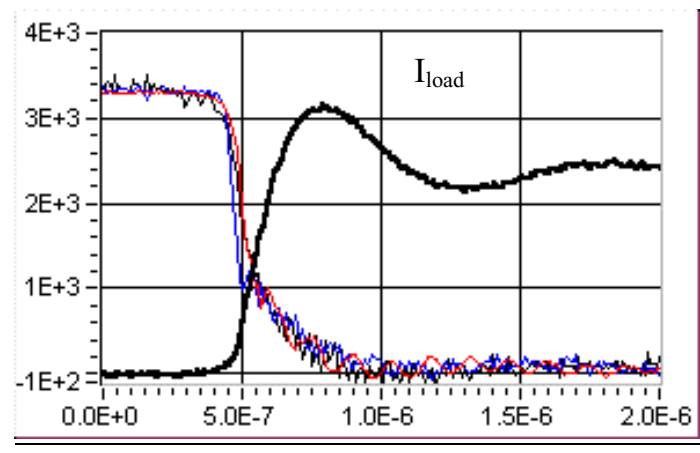

Figure 4. Voltage across each thyristor with compensation for loading by high voltage probes. PFN voltage is $10.0 \mathrm{kV}$.

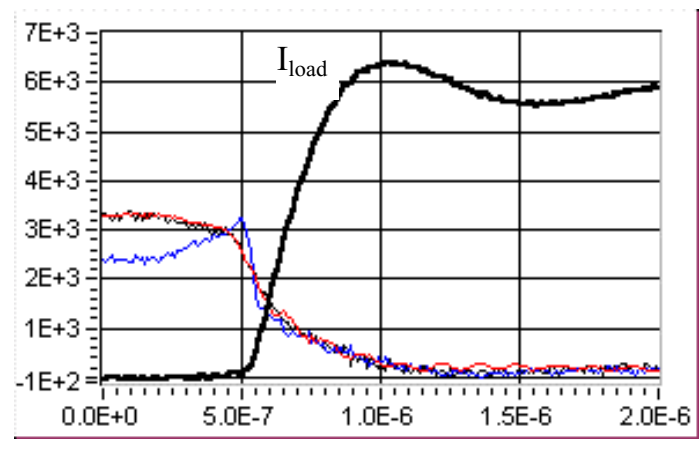

Figure 5. Voltage across each thyristor with deliberate mismatch for 1 device. PFN voltage is $9.0 \mathrm{kV}$.

\section{REPETITION RATE OPERATION, THERMAL PERFORMANCE}

The PFN was charged by a $1 \mathrm{~kJ} / \mathrm{s}$ capacitor charging power supply gated off for $25 \mu$ s during switching. Repetition rate testing was limited by the capacity of the power supply. Tests were performed at $\leq 60 \mathrm{pps}, 1.9 \mathrm{kA}$ peak and $23 \mathrm{~A}_{\mathrm{rms}}$ with the $0.56 \mu \mathrm{F}$ PFN; and at repetition rates of $\leq 24 \mathrm{pps}, 4.6 \mathrm{kA}$ peak and $35 \mathrm{~A}_{\mathrm{rms}}$ with the $1.68 \mu \mathrm{F}$ PFN. With this PFN operating at 35 $\mathrm{A}_{\mathrm{rms}}$, a $27 \mathrm{C}$ temperature difference from thyristor to heat sink was measured.

The thermal resistance of a the thyristor is $0.5 \mathrm{C} / \mathrm{W}$ to the bottom side of the $\mathrm{BeO}$ ceramic. The additional ceramic layer needed for $10 \mathrm{kV}$ insulation results in a ceramic-toceramic interface and a ceramic-to-metal heat sink interface. Several different interface materials were tested. A one part viscous, nonconductive epoxy, loaded with AlN powder, was used for most of the testing. This resulted in additional $0.6 \mathrm{C} / \mathrm{W}$ thermal resistance, due primarily to the thermal resistance at the interfaces, which was much higher than expected. Examination of the epoxy layers after testing show they were thicker than intended $(0.13$ to $0.16 \mathrm{~mm}$ instead of $0.05 \mathrm{~mm}$ ) and there were a large number of voids throughout the epoxy. It should be possible to obtain substantially better results. A high-conductivity thermal grease with a viscosity similar to the epoxy was also used, requiring a clamping mechanism to hold the thyristor/ceramic sandwich on the heat sink. We had better thermal performance with this arrangement. Unfortunately, the grease tended to flow out towards the edge of the ceramic, even after several days. Because the grease is a poor insulator, breakdowns occurred around the edge of the insulating ceramic, destroying the thyristor at the high voltage end of the module.

\section{FAULT MODE PERFORMANCE}

Experiments were conducted to examine the behavior of the switch under load fault conditions. To simulate a load fault, a spark gap was placed across the load resistors. The gap was adjusted to cause breakdown to occur during both the early and middle stages of the pulse. Because the thyristors used in the switch are not intended to conduct current in the reverse direction, a stack of three $5 \mathrm{kV}$ diodes were connected in parallel with the switch. Initially, there was no damping in the circuit other than the switch resistance.

Initial tests were performed using the switch to discharge a $1.68 \mu \mathrm{F}, 8 \mu \mathrm{s}$ PFN charged to $10 \mathrm{kV}$ into a $2.2 \mathrm{ohm}$ load. Figure 6 shows the results of breakdown of the load during the pulse. When a fault occurs, there is substantial reverse current conduction through the switch as the diode stack begins to conduct current. The peak current on the second positive halfcycle is approximately $95 \%$ of the initial. Also, there is no gate drive during the second and succeeding forward current cycles. The switch withstood many pulses of both early and late time breakdown of the load, at $<1$ pps repetition rate using this PFN, without failure. 
The same switch was then used with the nominal $6 \mathrm{kA}, 3 \mu \mathrm{s}, 1.68 \mu \mathrm{F}$ PFN. A much higher current and di/dt results for the same PFN energy as in previous tests. Figure 7 shows switch performance with the PFN charged to $6.5 \mathrm{kV}$ for early load breakdown. Again, there is substantial reverse current conduction through the switch before it turns off, and there is no gate drive during the second and succeeding forward current cycles.

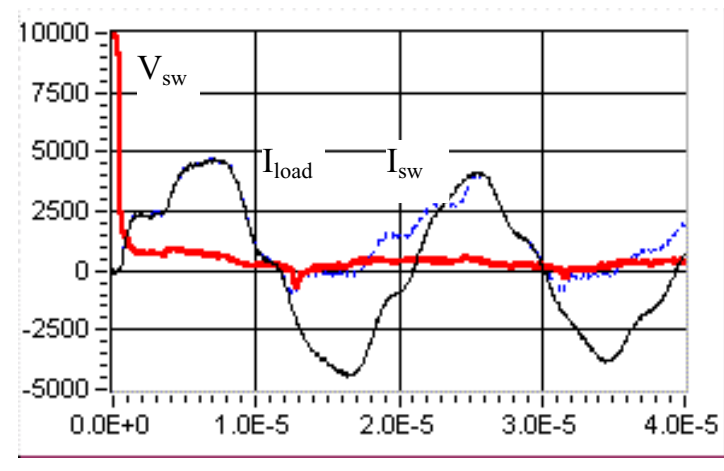

Figure 6. Load fault, $8 \mu$ s PFN. Switch voltage, $\mathrm{V}$, (bold), load current, A, and switch current, A, (dashed).

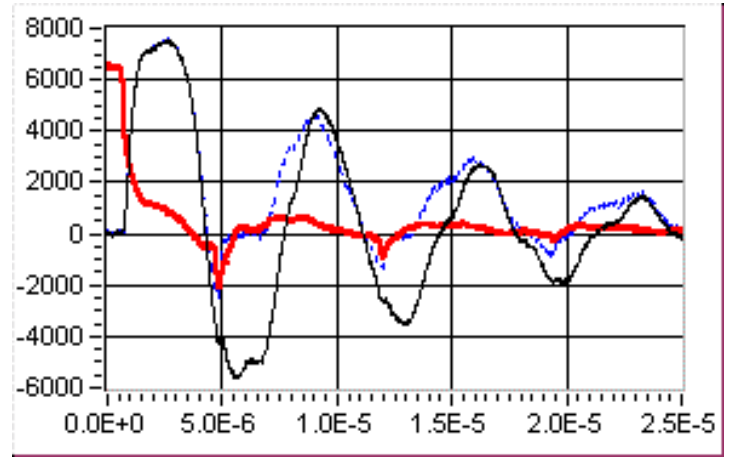

Figure 7. Load fault, $3 \mu$ s PFN. Switch voltage, V, (bold), load current, A, and switch current, A, (dashed)

After approximately 15 pulses at $6.5 \mathrm{kV}$, one of the three thyristors failed. Several pulses later, the remaining devices were destroyed. The waveforms for this pulse are shown in Figure 8. Careful examination of the switch current waveform shows that the switch stopped blocking reverse current during the third cycle. This indicates the devices were not destroyed by the initial over-current, but were instead destroyed during one of the succeeding forward current cycles, when the thyristors were forced to conduct current at high di/dt with no gate drive applied.

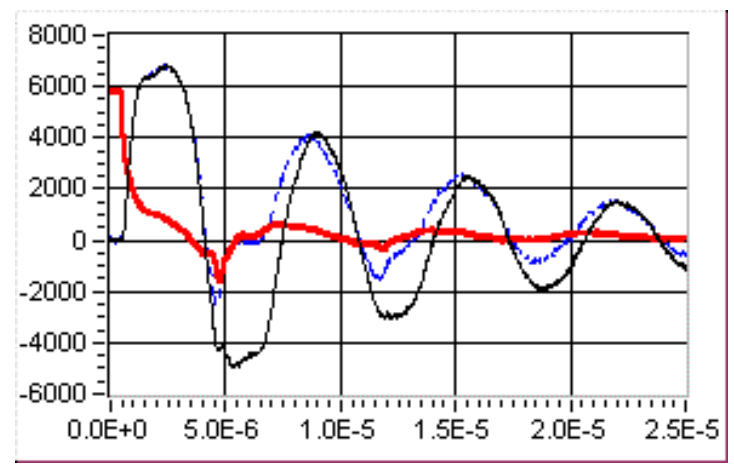

Figure 8. Load fault with switch failure.

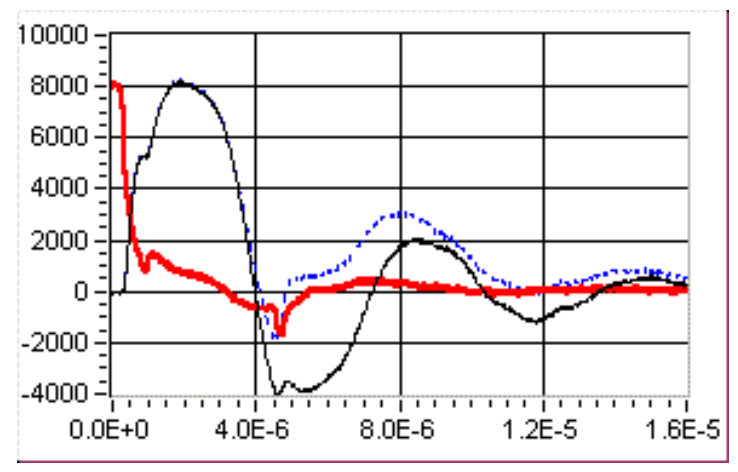

Figure 9. Load fault, $3 \mu \mathrm{s}$ PFN.

Switch voltage, V, (bold), load current, A, and switch current, A, (dashed); both figures.

Additional load fault experiments were conducted with a $0.2 \mathrm{ohm}$ damping resistor in series with the spark gap. With this resistance in place, the initial current reversal was limited to 50 percent. Operation for many pulses at fault currents $>8 \mathrm{kA}$ caused no damage to the switch. Figure 9 shows switch performance with the PFN charged to $8 \mathrm{kV}$ and breakdown in the middle of the load pulse.

\section{MULTI-MODULE TESTING}

Some experiments were performed using 2 and 3 modules connected in series, to switch a nominal $4 \mu \mathrm{s}$, 5-section, type E pulse-forming network with a total capacitance of $0.75 \mu \mathrm{F}$. The PFN and switch assembly were installed in a small tank to allow back-filling with $\mathrm{SF}_{6}$, 
for future operation at up to $50 \mathrm{kV}$. The load consisted of several bulk ceramic resistors connected in parallel for a combined resistance of $\approx 2 \mathrm{ohms}$.

Figure 10 shows a result of a 3 -module switch operating at $30 \mathrm{kV}$ and $7 \mathrm{kA}$. Peak $\mathrm{di} / \mathrm{dt}$ is approximately $20 \mathrm{kA} / \mu \mathrm{s}$. Because only three high voltage probes were available, one of which is used to monitor the load voltage, the voltage across each individual stage could not be monitored. The voltage across the switch and the voltage at one of the junctions between two modules was measured. Thus, figure 10b shows a comparison between the voltage across one stage and _ of the voltage across the other two stages. The excellent dynamic voltage-sharing shown in this figure was observed regardless of which module was monitored. For these measurements, resistors were placed across the appropriate modules to compensate for the probe resistance.

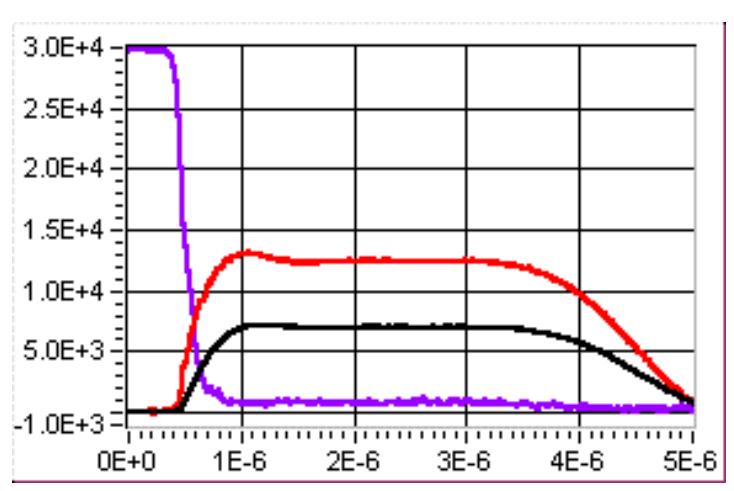

(a) Switch Voltage (V) after subtracting inductive voltage drop, load voltage $(\mathrm{V})$, and load current (A).

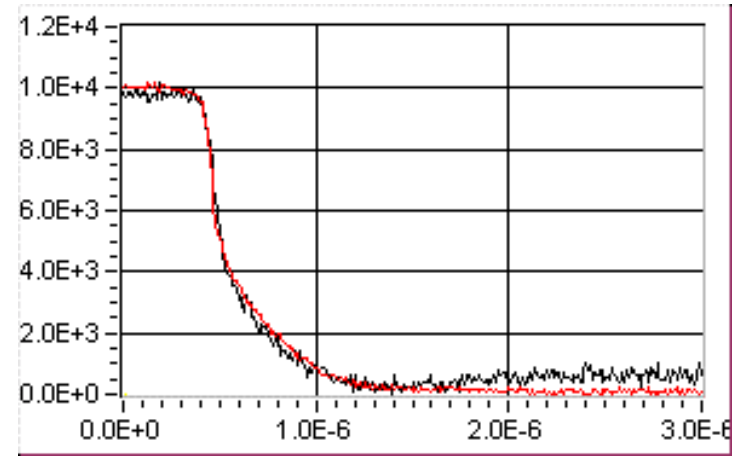

(b) Voltage (without subtracting inductive voltage drop) across modules 3 (lower) and 0.5 times the voltage across modules 1 and 2 .

Figure 10. Three module switch charged to $30 \mathrm{kV}$.

\section{SUMMARY}

This work has demonstrated that a $10 \mathrm{kV}$ module can operate reliably at currents up to $8 \mathrm{kA}$ with $\mathrm{di} / \mathrm{dt}$ 's of $>30 \mathrm{kA} / \mu \mathrm{s}$, and can withstand severe load faults. Repetition rates of up to $60 \mathrm{pps}$, limited by the high voltage power supply were demonstrated. Tests at $30 \mathrm{kV}$ with three modules connected in series, showed simultaneous turn-on with good voltage-sharing between modules.

Future effort will concentrate on improving the thermal performance of the switch to increase its power handling capability and minimize thermal fatigue. A new asymmetric (reverse conducting) thyristor package design will be implemented to minimize cathode inductance, reduce thermal impedance and eliminate the need for two layers of ceramic. The gate circuit will be modified to provide current over a longer time to improve the fault tolerance of the switch. A prototype $60 \mathrm{kV}$ switch that can be installed into a modulator in place of a hydrogen thyratron will be developed.

\section{REFERENCES}

1. J. C. Driscoll et al., "A High Speed Pulser Thyristor", Proceeding of the 1998 Applied Power Electronics Conference, Anaheim, California, Feb. 15-19, 1998.

2. J. C. Driscoll et al., U.S. Patent No. 5,592,118 Jan. 07,1997. 